\section{Familias digitales: Educando entre la ansiedad $Y$ la sorpresa}

Livingstone, S. \& Blum-Ross, A. (2020). Parenting for a Digital Future. How Hopes and Fears about Technology Shape Children's Lives. New York, NY: Oxford University Press. ISBN 9780190874728. 262 páginas.

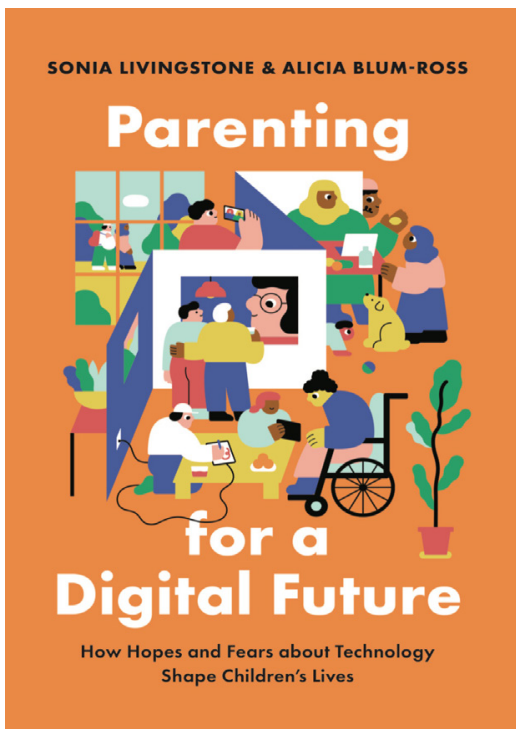

El incesante proceso de mediatización de la sociedad ha provocado grandes transformaciones en todas las dimensiones. Una de las esferas afectadas por la presencia masiva de los medios de comunicación es la vida familiar. Ya con la irrupción de la televisión, la relación entre padres/ madres e hijos/hijas se había tensionado, pero hoy con los smartphones, notebooks, tablets y otros múltiples dispositivos digitales esa tensión ha adquirido nuevas escalas.

Ese es el contexto de la exhaustiva investigación de Sonia Livingstone y
Alicia Blum-Ross plasmada en el libro Parenting for a Digital Future. How Hopes and Fears about Technology Shape Children's Lives. Este texto presenta principalmente la vida cotidiana de 73 familias londinenses, enfatizando como sujeto de estudio a padres y madres que deben lidiar con niños, niñas y adolescentes que están 24/7 conectados a sus juegos en línea, redes sociales digitales y aplicaciones en el celular de todo tipo.

Las autoras abandonan la posición normativa, aquella que penaliza el consumo mediático en los menores edad y llaman a alejarse de las pantallas. Más bien, Livingstone y BlumRoss asumen esta realidad multipantalla y la problematizan en el contexto material donde este consumo se desarrolla. No olvidan las distinciones de clases ni las relaciones de poder, pero desdramatizan las advertencias sobre la "toxicidad" de las plataformas digitales y construyen un texto que se lee más como crónicas de las familias que como una exposición de resultados de investigación. Todo, con la intención de responder una pregunta muy desafiante: “¿Cómo los padres pueden preparar a sus hijos para ser adultos en 2030 o 2040?" [How can parents prepare their children to be adults in 2030 or 2040?] (p. 6). Las posibles respuestas a esa pregunta cruzan los 7 capítulos de este estudio mixto (etnografía y encuestas).

\section{Métodos mixtos con primacía cualitativa}

Una de las principales cualidades de este libro es su originalidad para presentar los resultados de una rica investigación, que incluyó el registro diario de 73 familias entre 2015 y 2016, y una encuesta a 2.000 participantes en 2017 en Gran Bretaña. Las autoras y su equipo construyen un mapa de relaciones complejas entre adultos, niños y niñas, y los medios de comunicación presentes en las casas, de sectores ricos, medios y pobres. Es un trabajo detallado, una "descripción densa" en el más estricto sentido de Geertz (1973/1989), que permite observar las dinámicas cotidianas de las familia, desde cepillarse los dientes a las 7 de la mañana con el Ipad proyectando dibujos animados por Youtube y con el televisor contando las noticias del día anterior hasta las preguntas por el destino de sus hijos e hijas que se realizan padres y madres, que transitan permanentemente entre la ansiedad de un "futuro digital" cada vez más incierto y las sorpresas de las habilidades que ya poseen sus niños y niñas.

Ese ambiente mediático es retratado desde una mirada interdisciplinaria que conecta los aportes de los estudios en comunicación con la antropología y la psicología social. El relato se entreteje abandonando "el discurso público de la alienación familiar, donde supuestamente los padres están separados de sus hijos, quienes están conectados a sus pantalla y excluidos de la disciplina y moralidad", tal como escriben las autoras en la página 10.

Por el contrario, afirman las investigadoras, las relaciones dentro de las familias son cada vez más difíciles de categorizar. Por eso, optan por una investigación mixta, pero con un componente cualitativo dominante. Las historias de las familias nutren el texto en sus aspectos más centrales, donde la educación se convierte en uno de los mayores desafíos de los padres y madres, quienes se cuestionan todos los días si sus hijos e hijas están aprendiendo lo suficiente para enfrentar la vida adulta en un 
mundo que ellos ven absolutamente incierto. Saber programar, diseñar Apps y crear contenidos, parecieran ser temas más importantes que la tradicional tarea escolar, que esos padres y madres debieron cumplir a la edad de sus hijos e hijas. Es ahí cuando aumenta la ansiedad, ya que estos padres y madres se perciben en un espacio temporal muy distinto al de sus hijos e hijas, incapaces de responder a las demandas de la era digital, salvo los sectores más privilegiados, donde las familias pueden contratar servicios de ayudas especiales para atenuar estas brechas generacionales (capítulo 3).

\section{Clase, raza y poder en la era digital}

Justamente, uno de los resultados más evidentes que presenta el relato de estas 73 familias es la desigualdad con la que enfrentan temas como la alfabetización digital o el acceso a bienes culturales. Por cierto, no se trata de un hallazgo novedoso. El capital cultural, como lo advirtieron Bourdieu y Passeron (1964/2003) hace ya unas décadas, influye en las decisiones educacionales de las familias y determina muchas veces el éxito o fracaso en la trayectoria escolar de niños, niñas y adolescentes. Hoy, ese capital cultural, que siguiendo a las autoras es también digital, sigue modelando la manera en que las familias se relacionan con las escuelas.

Los padres y madres de los sectores pobres de Londres, que estudiaron las autoras, relatan las dificultades para cumplir con las demandas que impone el contexto educacional digital en el que se desenvuelven sus hijos e hijas. Mientras los sectores medios buscan alternativas a su alcance y los sectores altos disfrutan de ayudas personalizadas (profesores particulares de programación, por ejemplo), en los segmentos más desaventajados, principalmente familias inmigrantes o de minorías raciales, las posibilidades de un "consumo responsable y crítico" de los medios de comunicación se hace casi imposible. De hecho, una madre cuenta con culpa- que utiliza Youtube como una niñera para que su hija le permita dormir algunas horas antes de continuar con su segundo trabajo remunerado del día, pues con lo que recibe de su primer empleo apenas les alcanza para vivir.

Esta última historia es una de las más valiosas del texto, pues muestra en detalle que hacer afirmaciones tan categóricas como "alejar a los niños y niñas de las pantallas" es una ingenuidad en un contexto don- de las pantallas ocupan una serie de espacios sociales no observados por quienes las condenan. Esa riqueza cualitativa y su tono no moralizante son, a mi juicio, los principales aportes de este texto, que es sobre todo una interpelación a los padres y madres de la era digital.

\section{Cristian Cabalin}

Profesor Asociado

Universidad de Chile

Universidad Central de Chile

ccabalinauchile.cl

\section{Referencias}

Bourdieu, P. \& Passeron, J. C. (1964/2003). Los herederos. Los estudiantes y la cultura. Buenos Aires: Siglo XXI editores.

Geertz, C. (1973/1989). La interpretación de las culturas. Barcelona: Gedisa. 